\title{
THE ROLE OF ALCOHOL INVOLVEMENT IN MAXILLOFACIAL TRAUMA
}

\author{
Liudmil Gagov, Martin Rubiev, Elitsa Deliverska \\ Department of Oral and Maxillofacial Surgery, Faculty of Dental Medicine, \\ Medical University - Sofia, Bulgaria
}

ABSTRACT:

Introduction: Alcohol is regularly consumed by individuals in social settings. However, overindulgence can lead to impaired judgment and physical harm. Patients who have sustained alcohol - related injuries are frequently treated in departments of Oral and Maxillofacial surgery.This study exams the association between alcohol consumption and maxillofacial trauma treated at the Department of Maxillofacial surgery -'St. Anna' Hospital in Sofia for 5 years period.

Materials and methods: A minimum dataset was collected prospectively by maxillofacial staff after the first examination of an emergency referral. Information was entered on to a designed database and analysed for a 5-year period. Different data for the victims including age, sex, ethnic group, social status, type of fractures, mode of injury, and treatment delivered was gathered and analyzed.

Results: A total of 94 patients were identified to have alcohol-related injuries. More than 4/5 were male of which almost $70 \%$ are between 17 and 50 years old. Assault was the most often cause of trauma, followed by motor vehicle accident and fall as third reason for injuries. Other etiologies differ and were presented by fewer cases.

Conclusion: The maxillofacial region is by far the most frequently selected target in assault in adults. There is a casual link between alcohol intoxication and injury. Alcohol-related injuries continued to be the main problem in young male adults involved in fights. Significant problem are road accidents caused by alcohol-influenced drivers. Therefore we believe that there should be public awareness to educate these people for the harmful effect of drinking.

Key words: alcohol consumption, maxillofacial trauma

\section{INTRODUCTION:}

Alcohol intoxication leads to neurologic impairment; it can incite violence and aggression as well as render the individual vulnerable to injuries.1 Alcohol intoxication increases the risk of injury as a result of interpersonal violence (IPV) and motor vehicle accidents (MVA). In particular, the quantity of alcohol consumption has been shown to be more predictive of IPV-related injury than the frequency of drinking. Studies have consistently shown the face to be acommonly targeted region in alcohol-related violence. The association between alcohol and interpersonal violence is well-established, and studies from several countries have shown an increasing association between maxillofacial trauma and alcohol consumption Alcoholrelated injuries, especially facial fractures, mainly affect young adults. Alcohol overconsumption has continued to be a major social problem. The government in Bulgaria has found some success in outlawing drunk drivers by educating the public on the potential hazard of drunk driving and by punishing drunk drivers accordingly. However, there has not been a nationwide campaign addressing the close relationship between social drinking in young adults and IPV.

\section{MATERIALS AND METHODS:}

This study reviewed patients who were referred to department of maxillofacial surgery at'St. Anna' Hospital with alcohol-related facial injuries during a 5-year period from april 2005 to february 2010. The details were reviewed retrospectively via a trauma database at the department. Variables analyzed included demographics, diagnosis, mode of injury and sites of fractures. (Patients with facial lacerations without fracture were not included in this study). Alcohol use was documented when a patient was reported to have consumed alcohol or was injured by someone under the influence of the alcohol. Because blood alcohol level was not routinely tested due to legal constraint, clinical judgement and patient honesty were relied upon.

\section{RESULT:}

A total of 352 patients with the result of facial trauma were entered on to the database and 109 were with alcohol related facial trauma. 
Fig.1. Traumas related with alcohol consumption

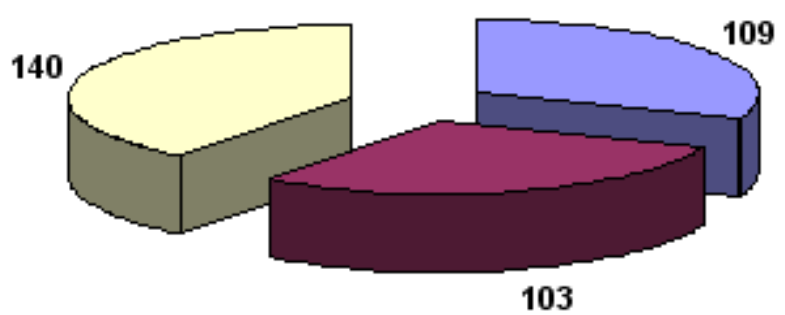

口Alcohol involvment $\square$ No alcohol involvment $\square$ No data

Fig.2. Aetiology

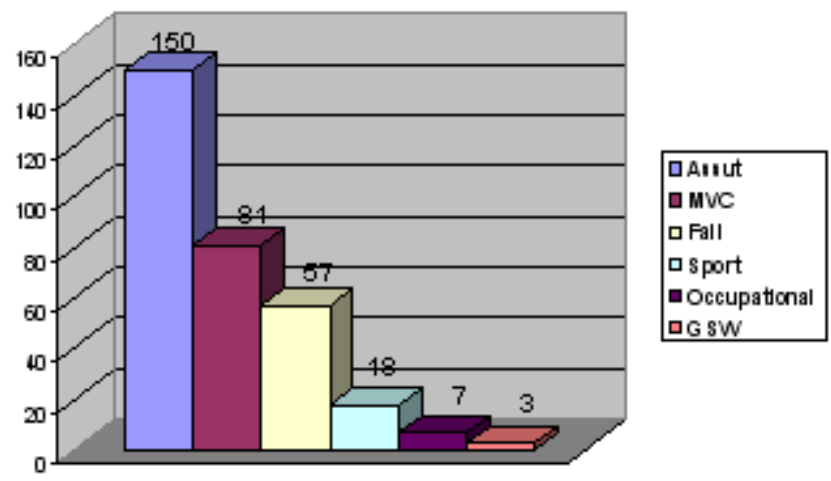

The most common etiology of trauma was assault (42.6\%) followed by car accident (23.1\%), fall (16.2\%), sports $(5 \%)$, occupational $(2 \%)$, and gunshot wound $(0.9 \%)$.Overall, $47 \%$ of our trauma referrals involved alcohol, but when this was limited to trauma caused by interpersonal violence, or assault, the association rose to $72 \%$. Falls made up $28 \%$ of our trauma referrals, and alcohol was involved in $24 \%$ of them. Road crashes made up only $5 \%$ of our trauma, but nevertheless $23 \%$ of these incidents involved alcohol, imbibed by either the injured driver or the injured pedestrian. Certain types of assault were more influenced by alcohol than others. Punches, kicks, bites and knife or glassassaults were heavily influenced by alcohol. The most common fracture type was mandible fractures $(31.1 \%)$ ( mandibular angle was the most common site of mandibular fracture) followed by nasal bone fracture $(29.3 \%)$.

The sex distribution showed an overall male-tofemale ratio $-9: 1$ and those in the age group most affected were between 20 and 55 years of age with the mean ageThere were 352 patients in the study period illustrates the yearly distribution. Males in the 16-30-year group predominated, accounting for $66 \%$ of the total. The proportion of alcoholrelated injuries remained high during the study period. IPV has increasingly become a pre- dominant cause, and MVA-related injuries have been on a steady decline. A high proportion of these patients were hospitalized and underwent surgery. Most of the referrals for alcohol related facial trauma we related to interpersonal Violence. Lacerations and fractures involving the mandible and zygoma were the most common maxillofacial injuries following trauma involving alcohol.

\section{DISCUSSION:}

The increasing availability, affordability, and acceptance of alcohol as a social tool have contributed to its becoming more of a social problem. Alcohol is implicated in MVA, but to a lesser extent than in IPV. MVA-related facial fractures are on a decline as a result of better driving conditions, improved car safety mechanisms, and education and public awareness campaigns of alcoholrelated trauma over the past decade. In Bulgaria, a strong stance taken by the government against drunk driving has contributed to the decline in alcohol-related MVA. Television advertisement discouraging drink driving has been particularly effective in warning the audience of its devastating consequence. Such interven-tional strategies are effective in reducing MVArelated facial fractures.

\section{CONCLUSION:}

In conclusion, this study shows that alcohol plays an important part in maxillofacial trauma, and that the association of interpersonal violence and alcohol is extremely high in Bulgaria.

Fig. 3. Age

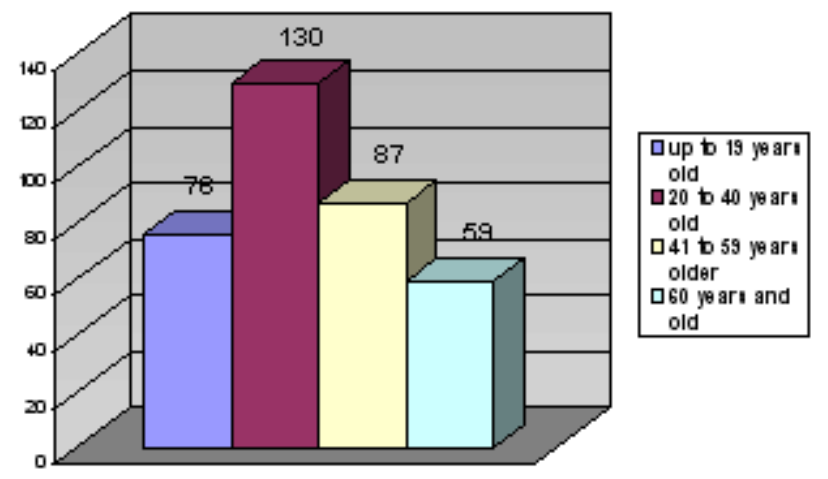


Fig.4. Type of injury

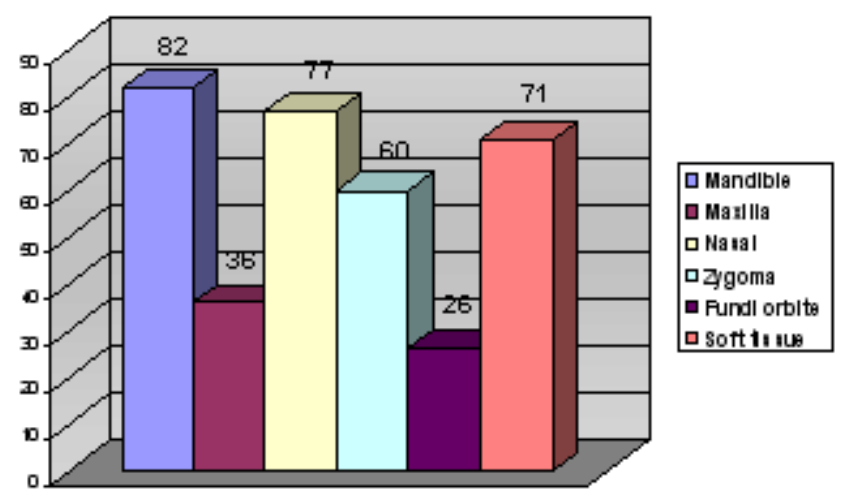

\section{REFERENCES:}

1. Smith AJ. Shepherd JP. Hodgson RJ. Brief interventions for patients with alcohol-related trauma. $\mathrm{Br} \mathrm{J}$ Oral Maxillofac Surg. 1998 Dec:36(6),408-415. [PubMed]

2. Warburton AL, Shepherd JP. Alcohol-related violence and the role of oral and maxillofacial surgeons in multiagency prevention. Int. J. Oral Maxillofac Surg. 2002 Dec; 31(6): 657-663. [PubMed] [CrossRef]

3. Lee K, Trend of alcohol involvement in maxillofacial trauma. Oral Surg Oral Med Oral Pathol Oral Radiol Endod. 2009
Apr;107(4):e9-13. Epub 2009 Feb 8. [PubMed] [CrossRef]

4. Laverick S, Patel N, Jones DC. Maxillofacial trauma and the role of alcohol. Br J Oral Maxillofac Surg. 2008 Oct;46(7):542-6. Epub 2008 Aug 6. [PubMed] [CrossRef]

\section{Adrress for correspondence:}

Elitsa Deliverska

Department of Oral and Maxillofacial surgery, Faculty of Dental Medicine, Medical University, Sofia

1, Georgi Sofiiski Str., 1431 Sofia, Bulgaria

E-mail: elitsadeliverska@yahoo.com 